\title{
Simulación probabilística de ingresos monetarios obtenidos en cultivos del sistema irrigado de producción de hortalizas del Valle del Sinú Colombia ${ }^{1}$
}

Oscar Burbano-Figueroa ${ }^{a, c,}$, , Janeth Alexandra Sierra-Monroyb, Adriana David Hinestroza ${ }^{c}$, Eike Luedeling $^{\text {d }}$

a University of Bonn, Center for Development Research (ZEF), Genscherallee 3, D-53113, Bonn, North Rhine Westphalia, Germany

b Instituto Colombiano Agropecuario (ICA), Laboratorio de Diagnóstico Fitosanitario - ICA Seccional Tolima (LDF - Tolima), Barrio Santa Helena, Ibagué, Tolima, Colombia

${ }^{c}$ Corporación Colombiana de Investigaciones Agropecuarias (AGROSAVIA), Centro de Investigación Turipaná, Vía Montería - Cereté Km 13, 230558, Cereté, Córdoba, Colombia

d University of Bonn, Department of Horticultural Sciences, Institute of Crop Science and Resource Conservation (INRES), Auf dem Hügel 6, D-53121, Bonn, North Rhine Westphalia, Germany.

\section{* Autor para correspondencia:}

Correo electronico: burbano.figueroa1@gmail.com

\section{Resumen}

En los sistemas de producción de hortalizas del Caribe colombiano, la diversificación en el uso de la tierra y productos a comercializar incrementa la complejidad del sistema. Estos sistemas requieren cuantificar la productividad y el riesgo asociado a cada uno de los cultivos seleccionados e identificar los factores limitantes de estos que afectan el retorno económico a fin de priorizar las opciones de inversión de recursos por parte de los agricultores e investigadores dedicados a estos sistemas. Para orientar este propósito, este estudio usó un enfoque de modelamiento participativo usando información cualitativa y cuantitativa del sistema de producción provista por agricultores del Valle del Sinú. La información cualitativa provista en grupos focales y entrevistas individuales fue organizado usando un enfoque de sistemas. La información cuantitativa relacionada con las variables del sistema fue extraída como probabilidades distribución después que los agricultores fueron entrenados para proveer estimaciones cuantitativas de variables. Modelo y valores de entrada para las variables fueron usados para construir una simulación probabilística que permitió i) estimar los ingresos esperados en los cultivos de hortalizas, e ii) identificar las incertidumbres críticas del

\footnotetext{
${ }^{1}$ Este documento es una versión en español de un documento en inglés que actúa como documento principal. No todos los autores han leído ambos documentos por problemas relacionados con la proficiencia en ambos idiomas y la función de cada documento. La versión en español actúa como documento de trabajo para evaluación de consistencia del modelo por participantes y expertos adicionales. Todas las recomendaciones a este documento son bienvenidas y pueden ser enviadas al correo del autor para correspondencia. Este documento puede ser libremente distribuido y puede ser citado como preprint incluyendo el número DOI asignado.
} 
sistema de producción. Los cultivos analizados fueron berenjena, ají dulce, papaya y habichuela. La simulación muestra que existe traslape de los rangos de distribución para ingreso (valor presente neto) y la relación costo-beneficio para estos cultivos. En consecuencia no existen ventajas de un cultivo sobre otro en términos de mayores beneficios y menores riesgos. La preferencia de un cultivo en particular podría ser explicada por las diferencias en la inversión requerida para cada cultivo, donde los agricultores con menor capacidad financiera prefieren sembrar cultivos de escasa inversión y ciclos más cortos (habichuela larga). El análisis de valor de la información permitió identificar las variables que más afectan los ingresos esperados del sistema de producción: precio de venta de los productos, pérdidas asociadas a plagas y enfermedades y rendimiento; se determinó que las variables asociadas a ají dulce son las de mayor importancia sobre el rendimiento esperado del sistema irrigado de producción de hortalizas en el Valle del Sinú.

\section{Introducción}

El Valle del río Sinú cubre una extensión de 763.493 ha, ubicadas en su totalidad en el departamento de Córdoba perteneciente a la región Caribe Colombiana. El paisaje predominante corresponde a tierras planas aluviales sujetas a sequías e inundaciones periódicas; es en esta planicie conocida como Sinú Medio donde se concentran los cultivos de hortalizas, ubicados en los municipios de Montería, Cereté, Ciénaga de Oro, San Carlos, y San Pelayo (CVS, 2019). La concentración de los cultivos de hortalizas ${ }^{2}$ en estos municipios, posiblemente está asociada a la mayor densidad poblacional del Sinú Medio y acceso al Distrito de Riego de Mocarí (DRM). El DRM es el sistema de riego y canales de drenaje más grandes del país con un potencial de área de irrigación de 43.000 hectáreas (IGAC, 2017; MADR et al., 2006).

El fomento de los cultivos de hortalizas en el país y el mejoramiento de las condiciones de vida de los agricultores dedicados a estos cultivos está a cargo de la Asociación Hortofrutícola de Colombia (ASOHOFRUCOL), organización sin ánimo de lucro encargada de administrar el Fondo Nacional de Fomento Hortofrutícola (FNFH) por delegación del Ministerio de Agricultura y Desarrollo Rural de Colombia (MADR). Durante los años 2010-2011, la región Caribe enfrentó incrementos drásticos de precipitación asociados al fenómeno de "La Niña" que inundaron el Valle del Sinú y arrasaron los cultivos de maíz y algodón, causando la ruina de los agricultores, especialmente de los minifundista. Fue en esta crisis que ASOHOFRUCOL visualizó una oportunidad para fomentar el cultivo de hortalizas y motivó a los productores a asociarse y diversificar su actividad, de tal forma que pudieran acceder a los beneficios del programa de Desarrollo Rural con Equidad del MADR.

En este escenario, fue constituida en el año 2012 HORTYFRU, la asociación de agricultores de hortalizas del Valle del Sinú con 36 socios fundadores. Esta asociación ha recibido apoyo institucional para el fortalecimiento de sus capacidades técnicas, especialmente de la Corporación Colombiana de Investigación Agropecuaria (AGROSAVIA). Estas intervenciones les permitió superar el balance económico negativo de los dos primeros años como cultivadores de hortalizas (David

\footnotetext{
${ }^{2}$ En este documento, el término hortalizas o cultivos hortícolas es usado en el contexto de la literatura anglosajona. Así, los cultivos hortícolas incluyen verduras, frutas y nueces que son usados directamente para consumo humano, además de flores y otras plantas ornamentales usadas con fines estéticos y plantas medicinales. Esta clasificación es apropiada en términos de describir las características específicas del sistema de producción de hortalizas (escala de producción y mercadeo de productos frescos) en comparación con los cultivos a gran escala de productos almacenables (algodón, arroz, trigo). Esta definición amplia de hortalizas es muy cercana a la aceptada por la Real Academia de la Lengua Española (RAE). La RAE no reconoce el significado "taxonómico" con que se hace uso en de la palabra hortalizas en el español coloquial y la define simplemente como "Planta comestible que se cultiva en las huertas".
} 
Hinestroza, 2020). Aun con estas intervenciones, los agricultores de HORTYFRU enfrentan múltiples incertidumbres relacionadas con las variaciones en costos de producción, rendimiento de los cultivos y precios de los productos, que derivó en su interés por participar en la estimación de los riesgos asociados a las especies hortícolas usadas en su sistema de producción.

La investigación e innovación en cultivos hortícolas enfrenta múltiples retos a nivel nacional y local, especialmente de índole financiera, por tal razón, con frecuencia la investigación no llega a los pequeños productores, porque se enfoca en los cultivos de grandes extensiones; en este sentido, la innovación en sistemas de producción de hortalizas en el Valle del Sinú es principalmente el resultado de las iniciativas de los pequeños agricultores en su intención de mejorar sus ingresos. El ejemplo de mayor relevancia es el uso de landraces ${ }^{3}$ en el cultivo de berenjena, para las cuales los agricultores lideran una iniciativa para su reconocimiento como variedades por parte de ICA. Para estos landraces, no hay reportes de rendimientos o caracterización de sus características fisicoquímicas.

En presencia de montañas, el paisaje es altamente heterogéneo como resultado de la complejidad climática y topográfica, y la intervención humana (Chapin et al., 2002; García-Llamas et al., 2018; Loughlin et al., 2018). La heterogeneidad del paisaje colombiano asociado a la Cordillera de los Andes provoca una distribución fragmentada de los cultivos de una especie en particular o la existencia de sistemas de producción en ambientes disímiles. En este escenario, AGROSAVIA, la agencia nacional ${ }^{4}$ encargada de liderar la investigación e innovación en el sector agrícola y pecuario, debe desarrollar su rol misional. A fin de lidiar con este reto, esta institución canaliza los esfuerzos de investigación a través de las redes de innovación (RIN), que tienen carácter nacional pero están conformadas por investigadores de centros regionales, quienes abordan los problemas de los sistemas de producción.

Los sistemas de producción de hortalizas en el Caribe son sistemas diversificados de producción (patios de producción, sistemas de producción mixta, y/o sistemas agroforestales), marginales en términos de inversión pública, y dominados por landraces. Las RIN involucradas en este caso (Red de Hortalizas y Plantas Medicinales y la Red de Frutales) son las responsables de priorizar las especies de cultivo y problemas de los sistemas de producción a ser atendidos en función de la limitación de recursos de investigación disponibles. En este escenario, se desarrolló este estudio que tiene como objetivos: i) estimar los ingresos esperados en los cultivos de hortalizas en sistemas irrigados empleados por los agricultores del Valle del Sinú representados en la asociación de agricultores HORTYFRU, ii) identificar las incertidumbres críticas de cada uno de los cultivos empleados en el sistema de producción y su impacto en términos monetarios, y iii) proveer recomendaciones para reducir la pérdida de ingresos en el sistema de producción y las áreas en las que los esfuerzos de investigación deben concentrarse.

\footnotetext{
${ }^{3}$ Landrace es la designación para variedades domesticadas de plantas adaptadas a las condiciones locales del sistema de producción desarrolladas por comunidades de agricultores a través del tiempo y mantenidas en aislamiento de otras poblaciones de la misma especie. Un landrace es diferente de un cultivar en términos de estandarización. Los especímenes de un landrace son relativamente uniformes en términos genéticos pero son más diversos que los miembros de un cultivar (variedad vegetal obtenida por mejoramiento). En Colombia, el término usado para landrace es variedades criollas, locales, o regionales, o la adición del adjetivo criollo al nombre del cultivo, v.g., aguacates criollos.

${ }^{4}$ Colombia es una república donde la autoridad está compartida entre un gobierno central y unidades políticas constituyentes. Estas unidades se denominan Departamentos y tienen representación ejecutiva con un jefe de gobierno (gobernador) elegido de manera democrática. El gobierno central ha delegado autoridad en entidades con representación en todo el país, que en este documento serán denominadas agencias nacionales.
} 


\section{Materiales y Métodos}

\section{Descripción del área de estudio}

Este estudio describe el sistema irrigado de producción de hortalizas del Valle del Sinú (SIPH-VS), en el Caribe colombiano. El Valle de Sinú se divide de sur a norte en tres regiones llamadas Valle de Sinú alto, medio y bajo. Esta investigación se centra en los sistemas de producción ubicados en el Valle Medio de Sinú, que exhibe un clima húmedo de sabana (Aw) (Ortiz Guerrero et al., 2007)

\section{Recopilación de datos}

Los datos utilizados para construir el modelo conceptual y la simulación se obtuvieron de grupos focales y entrevistas semiestructuradas desarrollada con miembros de la asociación de agricultores HORTYIFRU ubicada en el municipio de Cereté; quienes se desempeñan como expertos en conocimiento para proporcionar información que describe el sistema de producción de hortalizas y los cultivos usados: berenjena (Solanum melongena), ají dulce (Capsicum annum), papaya (Carica papaya) y habichuela larga (Vigna unguiculata subsp. Sesquipedalis). El modelo y valores para las variables de entrada fueron revisados adicionalmente por 2 asesores de cultivos con educación disciplinaria en agronomía.

Doce agricultores participaron como el grupo central de expertos para verificar el modelo conceptual y la estimación de valores para las variables de entrada. Estos fueron capacitados como expertos calibrados utilizando un protocolo previamente descrito (Hubbard, 2010). Este protocolo requiere el uso de preguntas de contexto loca. Para este estudio, un conjunto de cien preguntas adaptadas al escenario local colombiano fue desarrollado.

\section{Construcción del modelo conceptual}

El modelo se construyó a partir de la información recolectada utilizando un protocolo descrito previamente para el modelado conceptual de agroecosistemas (Lamanda et al. 2012). El protocolo incluye los siguientes pasos:

(i) Análisis estructural para identificar los límites del sistema, subsistemas, componentes, factores que afectan el sistema y los indicadores para evaluar el desempeño del sistema.

(ii) Análisis funcional para identificar las relaciones entre los componentes del sistema, los factores y los indicadores de desempeño.

(iii) Análisis dinámico para describir cómo se comporta el sistema, los subsistemas y los componentes principales en el tiempo y para verificar si los modelos conceptuales estructurales y funcionales son capaces de representar la dinámica del sistema.

(iv) Análisis de consistencia para asegurar que el modelo conceptual como representación del conocimiento corresponde a la realidad. Este último paso es un proceso iterativo, aplicado regularmente durante los primeros tres pasos con la participación de expertos en conocimiento. Para una evaluación final de la coherencia del modelo conceptual, se publicó una versión en español de este documento como preprint para retroalimentación de un público más amplio de expertos.

\section{Escala espacial y temporal del modelo y simulaciones}

El sistema irrigado de producción de hortalizas del Valle del Sinú incluye varios cultivos o subsistemas de producción (sSP), que los agricultores emplean como alternativas de diversificación 
de sus opciones de inversión y obtención de ingresos (Tabla 1). Esta es la escala a la cual está descrito el modelo conceptual y las simulaciones aquí presentadas. Para cada subsistema de producción, el área de las parcelas y el número de fechas de siembra fue incorporado en las ecuaciones y agregado como datos anuales. En estas condiciones el modelo tiene una resolución espacial de parcela y una resolución temporal de un año.

Las principales alternativas de cultivos son: berenjena, ají dulce, habichuela larga o papaya, y corresponden a los sub-sistemas de producción dentro del SIPH-VS para los cuales las simulaciones y estimaciones de ingresos económicos son desarrolladas. El horizonte temporal para la evaluación del desempeño de los subsistemas de producción (ingreso económico) es de 5 años que corresponde al periodo de reposición del sistema de riego. El sistema de riego determina espacialmente las unidades de producción. Las parcelas de cultivos se distribuyen dentro del área irrigada, conformando las unidades de producción. El sistema de riego estándar usado por los agricultores cubre una superficie de 3 hectáreas (Tabla 1).

El modelo conceptual (Figura 1) contiene una descripción de los componentes de los subsistemas de producción representados en categorías o subsistemas: 1. Subsistema financiero, que enmarca los costos de irrigación del sistemas y su mantenimiento, mantenimiento de producción, arrendamiento de la tierra; con unas variables de costos de operación, tales como costos de irrigación, producción y usos del distrito de riego; 2. Subsistema de decisión, que comprende la escogencia del cultivo, número y área de la parcela; 3 . Subsistema técnico, de irrigación de la parcela (el sistema de irrigación y operación) y mantenimiento de la parcela (manejo de plagas, enfermedades y del cultivo); 4. Subsistema biológico, representado en la disponibilidad de agua, presencia de plagas y enfermedades, pérdidas físicas y mantenimiento del cultivo (Figura 1).

\section{Parametrización del modelo y ecuaciones}

Aproximaciones numéricas para los valores de las variables y parámetros de las ecuaciones fueron obtenidas usando protocolos previamentes descritos basados en en los principios de Economía de la Información Aplicada (Hubbard 2010; Hubbard and Millar 2014; Hubbard Decision Research 2015; Luedeling et al. 2014; Luedeling et al. 2015; Luedeling and De Leeuw 2014; Yigzaw et al. 2019). En resumen, los expertos en cada uno de los cultivos fueron entrenados para estimar los rangos de valores para parámetros y variables. El entrenamiento consistió en incrementar la comprensión y percepción de los conceptos de probabilidad e intervalos de confianza con el propósito de incrementar la habilidad para proveer de estimaciones numéricas de la realidad. Los expertos fueron invitados a proveer aproximaciones cuantitativas de las relaciones descritas en el modelo conceptual para poder ser convertidas en ecuaciones.

\section{Simulaciones}

Las ecuaciones matemáticas que describen las relaciones en el modelo y los rangos estimados para las variables y parámetros fueron usados para crear simulaciones probabilísticas usando el método Monte Carlo implementado en el paquete DecisionSupport del software R (Luedeling et al. 2018). 
Tabla 1. Descripción del sistema de producción de hortalizas bajo riego en el Valle de Sinú

\begin{tabular}{|l|l|}
\hline $\begin{array}{l}\text { Componente } \\
\text { del sistema }\end{array}$ & \multicolumn{1}{c|}{ Descripción } \\
\hline \multirow{3}{*}{$\begin{array}{l}\text { Unidades de } \\
\text { producción }\end{array}$} & $\begin{array}{l}\text { El sistema de riego estándar está diseñado para cubrir 3 hectáreas con control de riego en } 0.5 \text { ha. } \\
\text { Las áreas de riego pueden variar, pero independientemente del tamaño o forma del lote este es el } \\
\text { patrón modal. Dentro de cada parcela de 0.5 ha, se establecen líneas de riego específicas acordes } \\
\text { anualmente. }\end{array}$ \\
\cline { 2 - 3 } & $\begin{array}{l}\text { Las unidades de producción generalmente se establecen en terrenos arrendados. El tamaño de la } \\
\text { unidad de producción no está limitado por la disponibilidad de tierra, sino por la creciente } \\
\text { complejidad del sistema que aumenta los costos de manejo del cultivo por hectárea y reduce los } \\
\text { rendimientos esperados }\end{array}$ \\
\hline $\begin{array}{l}\text { Sistemas de } \\
\text { subproducción } \\
\text { (sSP) }\end{array}$ & $\begin{array}{l}\text { Las unidades de producción contienen múltiples especies de hortalizas y productos hortícolas. Sin } \\
\text { embargo, cuatro de éstos son los más comunes plantados con berenjenas y aji dulce que son la } \\
\text { opción favorita y se plantan regularmente }\end{array}$ \\
\hline
\end{tabular}




\section{Producción hortícola en el Valle del Sinú}

Los cultivos hortícolas en el valle de Sinú se producen en condiciones de riego y de secano. A nivel local, los sistemas de producción de secano se denominan "tradicionales", en referencia al hecho de que utilizan prácticas agrícolas "antiguas" sin la incorporación de técnicas modernas como la fertilización o riego, se desarrollan en unidades de producción que se limitan a jardines o patios traseros con no más de 0.5 ha, con un nivel de tecnología incipiente y dependencia absoluta de las condiciones de fertilidad natural del suelo y disponibilidad de lluvias. La dependencia de las lluvias limita estos cultivos a dos fechas de siembra coincidentes con las temporadas de lluvias.

En contraposición, los sistemas de riego se denominan "tecnificados" debido a la mayor intensificación de la inversión y la producción asociada con el uso de sistemas de riego y fertilización, y a su implementación en unidades de producción de mayor tamaño (3 hectáreas). No obstante, en los dos sistemas de producción se utilizan operaciones técnicas similares para la siembra, mantenimiento de cultivos y manejo de plagas y enfermedades. El material vegetal predominante en ambos sistemas de producción son landraces, que por su naturaleza son materiales heterogéneos en términos de rasgos fenotípicos, origen de semillas y calidad. En relación a la producción, los sistemas de riego reportan rendimientos más altos en comparación con los de secano y más libertad para elegir las fechas de siembra, lo que resulta en mayores oportunidades para capturar las ventanas de tiempo con mejores precios.

\section{Descripción del sistema de producción}

Los principales cultivos incluidos en los sistemas de producción irrigados son berenjena y ají dulce. Dos cultivos adicionales son seleccionados en menor preferencia por los agricultores: papaya y habichuela larga. Estos cultivos presentan rasgos contrastantes en cuanto a la fenología e inversión. El cultivo de papaya requiere una mayor inversión inicial y es de ciclo largo (hasta dos años), en cambio las habichuelas requieren una menor inversión y el período de crecimiento es corto (cuatro meses), razón por la cual son utilizadas como "cash crop".

\section{Descripción de los principales factores de reducción del rendimiento}

Los cultivos hortícolas en el Valle del Sinú son afectados principalmente por enfermedades transmitidas por el suelo y varias plagas, principalmente ácaros y cicadélidos (Tabla 2). Las enfermedades transmitidas por el suelo son comunes durante la temporada de lluvias cuando los campos se inundan. Los ácaros más comunes en estos cultivos son los ácaros rojos (Tetranychus ludeni) y el ácaro blanco (Poliphagotarsonemus latus). En el Valle de Sinú, son comunes durante la estación seca y afectan principalmente los cultivos de berenjenas y aji dulce. La presencia de cicadélidos (Empoasca sp.) es común en los cultivos de habichuela y papaya. Estas plagas se reportan comúnmente atacando diversidad de cultivos en todo el mundo.

\section{Simulación de los subsistemas irrigados de producción de hortalizas en el Valle del Sinú}

Las figuras 2 a 5 describen el ingreso esperado y variables limitantes para los subsistemas irrigados de producción de hortalizas del Valle del Sinú. Cada simulación (Figura 2, 3, 4 y 5) muestra para cada cultivo en cuatro paneles: la distribución de ingresos esperada en el horizonte de tiempo de 5 años en millones de pesos, el flujo de caja durante ese mismo periodo, el valor de información y la importancia de las variables. 
Tabla 2. Principales factores biologicos de reduccion del rendimiento en los cultivos usados en los sistemas de producción irrigados de hortalizas del Valle del Sinú

\section{Factores reductores}

del rendimiento

Descripción

\section{Berenjena (Solanum melongena)}

Pudrición del fruto

Patógenos asociados al marchitamiento vascular

Acaro rojo
Es una enfermedad común durante la estación de lluvias provocando daños en el campo y en los frutos almacenados. La evidencia experimental sugiere que el agente causal es Phytophthora spp.

El declive y la muerte de las plantas es muy común durante la temporada lluviosa asociada con patógenos bacterianos y fúngico. Ralstonia, Phytophthora y Fusarium son los comúnmente reportados, siendo Ralstonia el más limitante.

Tetranychus ludeni es la principal plaga para los cultivos de berenjenas en la región Caribe. Las variedades locales de berenjenas utilizadas en la región exhiben resistencia de campo contra esta plaga.

\section{Ají dulce (Capsicum annum)}

Damping-off

Enrollamiento foliar y clorosis

Ácaro blanco
Colapsos y muerte de plantas de pimiento asociadas a patógenos transmitidos por el suelo. La gravedad aumenta cuando los campos se inundan.

Causa desconocida. Los síntomas sugieren infección por virus posiblemente transmitido por áfidos.

Polyphagotarsonemus latus es una plaga ubicua que ataca los cultivos durante todo el año

\section{Habichuela verde (Vigna unguiculata)}

\section{Roya de la hoja \\ Pudrición radicular \\ Patogeno no identificado \\ Fusarium, Sclerotium y Phytium}

Lorito verde

Picudos
Empoasca sp puede reducir la temporada de cosecha a solo 2 meses. Esta plaga posiblemente está asociada a la transmisión del virus responsable de la clorosis y enrollamiento foliar.

Plaga no identificada que causa daño a los brotes de flores provocando su pérdida y la generación de puntos negros sobre las vainas de la habichuela larga. Este daño disminuye el valor del producto en el mercado.

\section{Papaya (Carica papaya)}

\section{Antracnosis}

Variola

Lorito verde
Esta enfermedad de la fruta es constante durante todo el año con un mayor impacto durante la temporada de lluvias.

Enfermedad de la mancha negra de la papaya causada por Asperisporium caricae

Probablemente individuos de la especie Empoasca papayae. Esta peste provoca defoliación y pérdida del rendimiento asociada al consumo de hojas y a la transmisión de la enfermedad bunchy top 


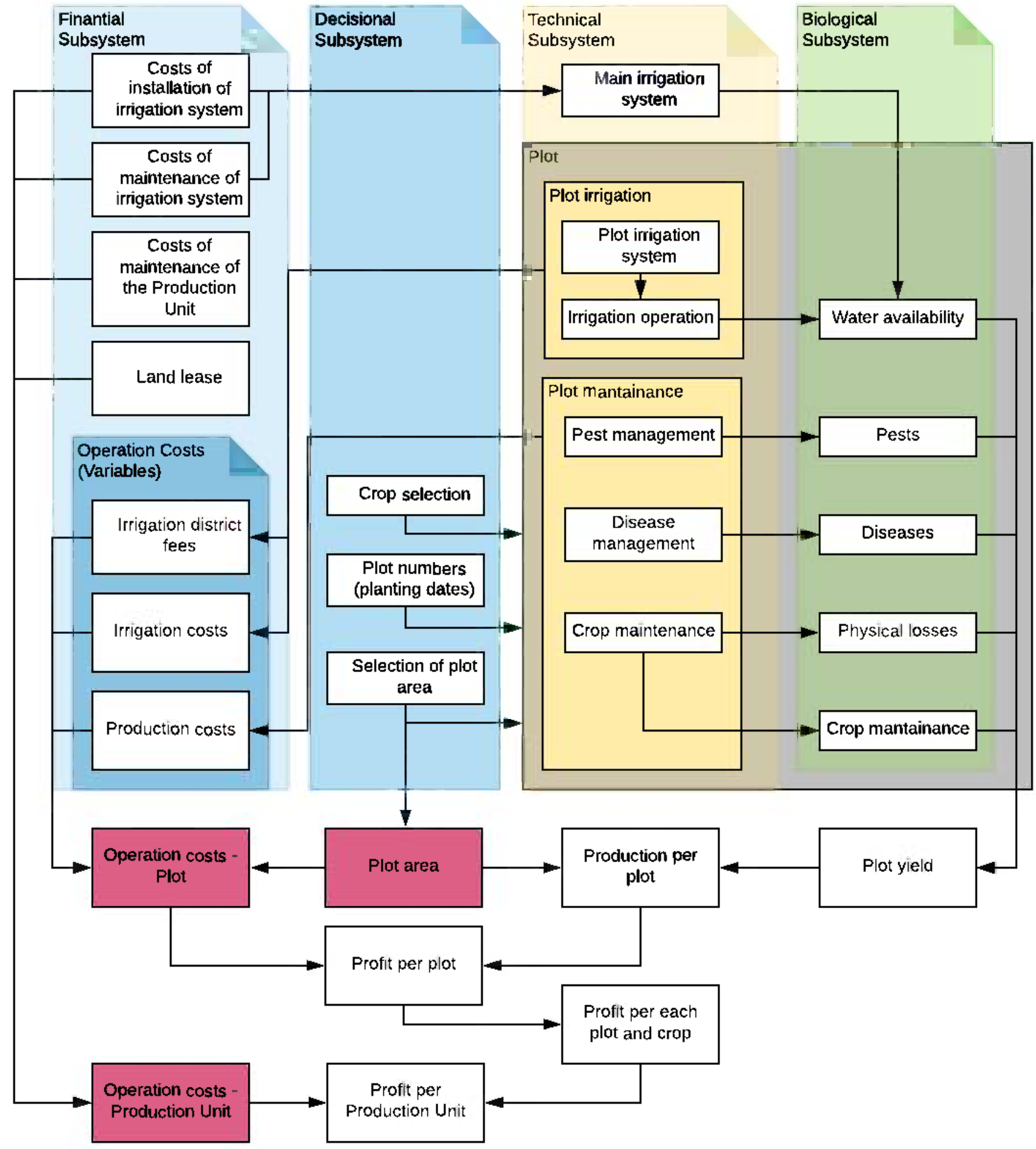

Figura 1. Modelo conceptual del sistema irrigado de producción de hortalizas del Valle del Sinú (SIPH-VS) representado a escala de parcela del cultivo dentro de la unidad de producción. La unidad de producción está definida por el sistema de riego estándar usado por los agricultores que corresponde una superficie irrigada de 3 hectáreas. Las principales alternativas de cultivos en estas unidades de producción son: berenjena, ají dulce, habichuela larga o papaya. 

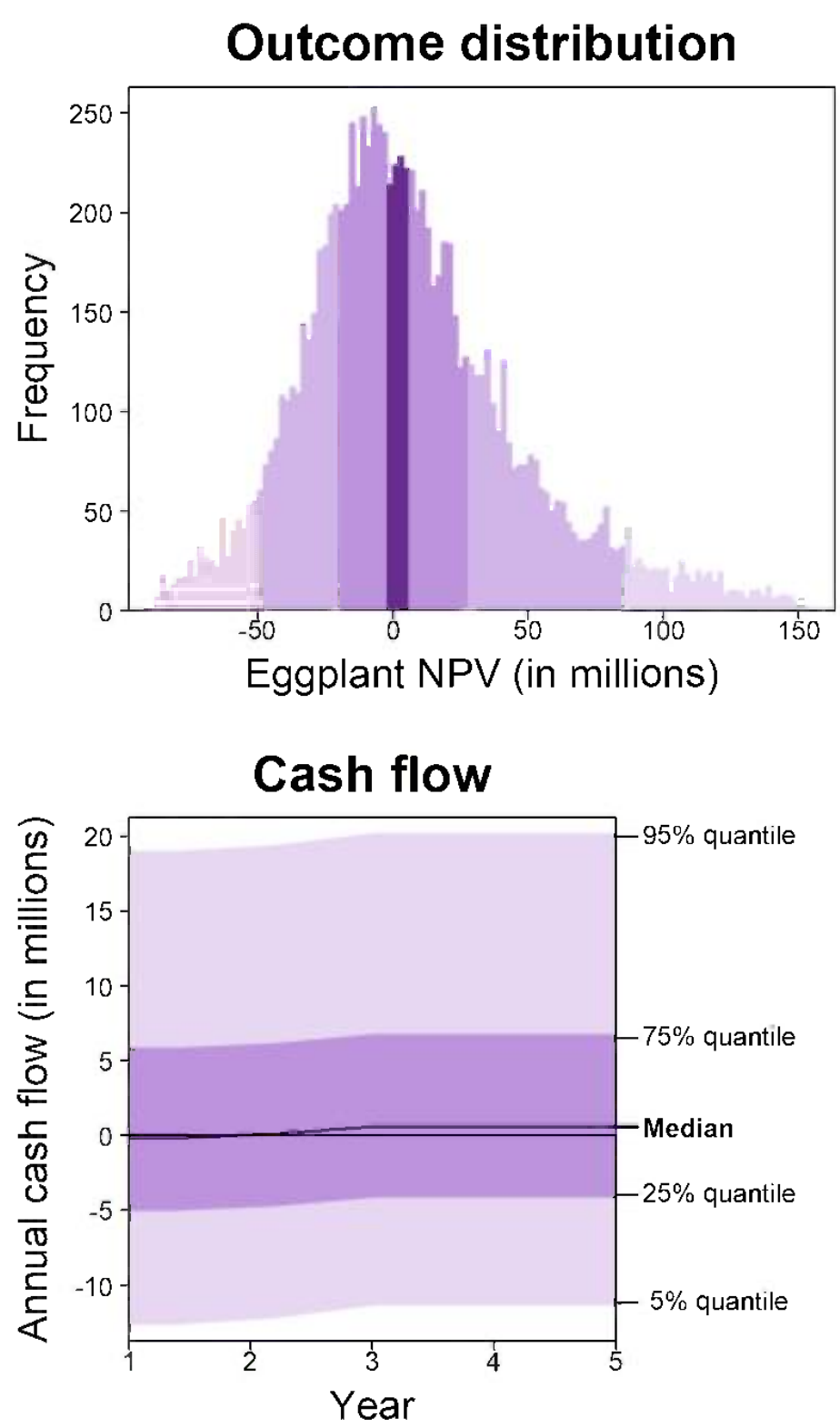
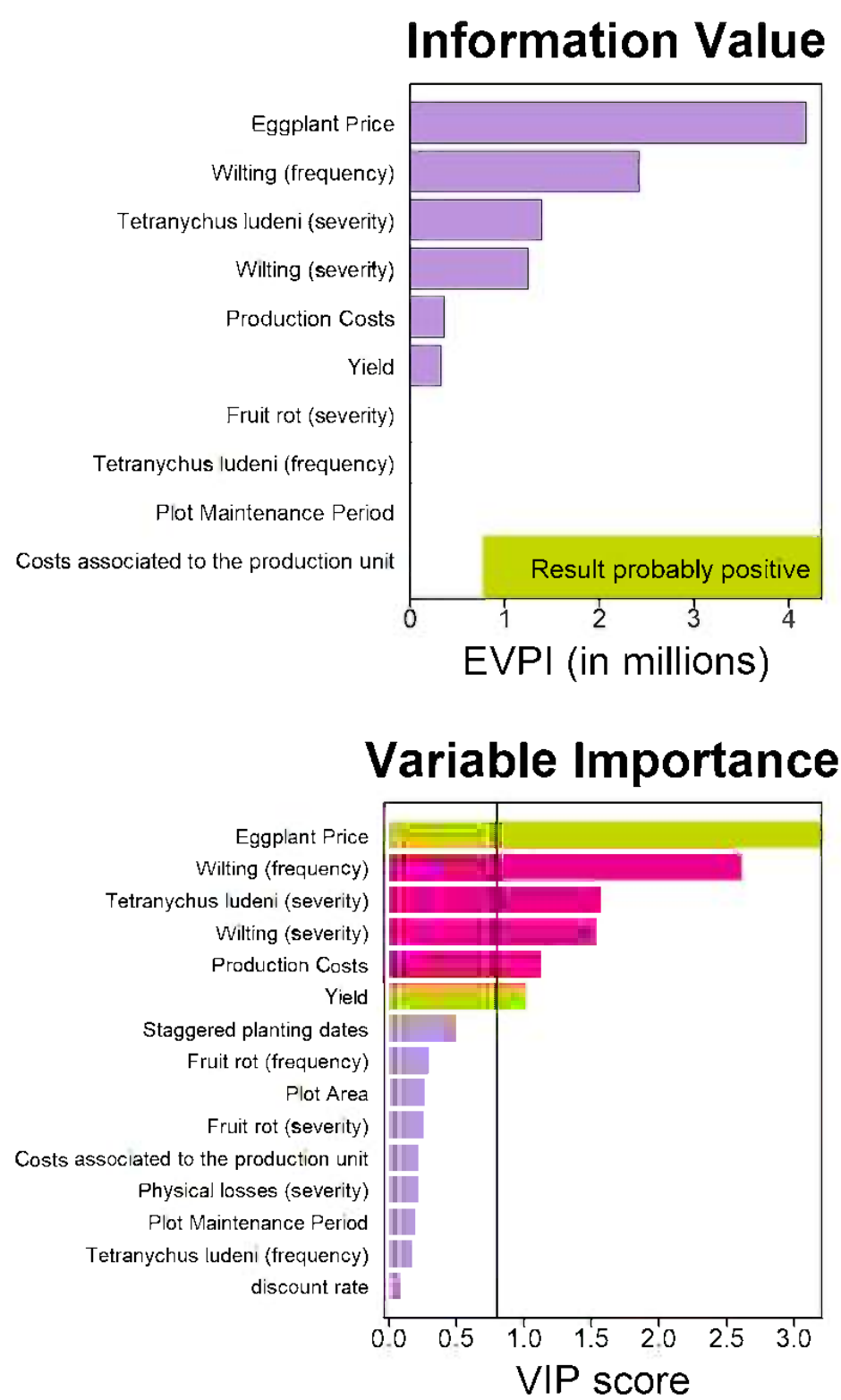

Figura 2. Resultados del modelo de simulación para la producción de berenjena (eggplant) en los sistemas irrigados de producción hortícola de Valle del Sinú, Córdoba, Colombia (con 10,000 ejecuciones de modelos) con un horizonte temporal de cinco años. Outcome Distribution: Distribución de utilidades proyectada en millones de pesos colombianos (mCOP) como valor presente neto (NPV) (arriba a la izquierda). Information Value: Valor de la información en mCOP estimada como Valor esperado de la información perfecta (EVPI) (arriba a la derecha). Cash Flow: Flujo de caja del cultivo en mCOP por año (abajo a la izquierda). Variable Importance: Importancia de las variables (VIP score) determinadas por regresión de mínimos cuadrados parciales. Las variables con un valor VIP > 0.8 (línea vertical negra) están marcadas en verde (correlación positiva) o en rosado (correlación negativa) (abajo a la derecha). 

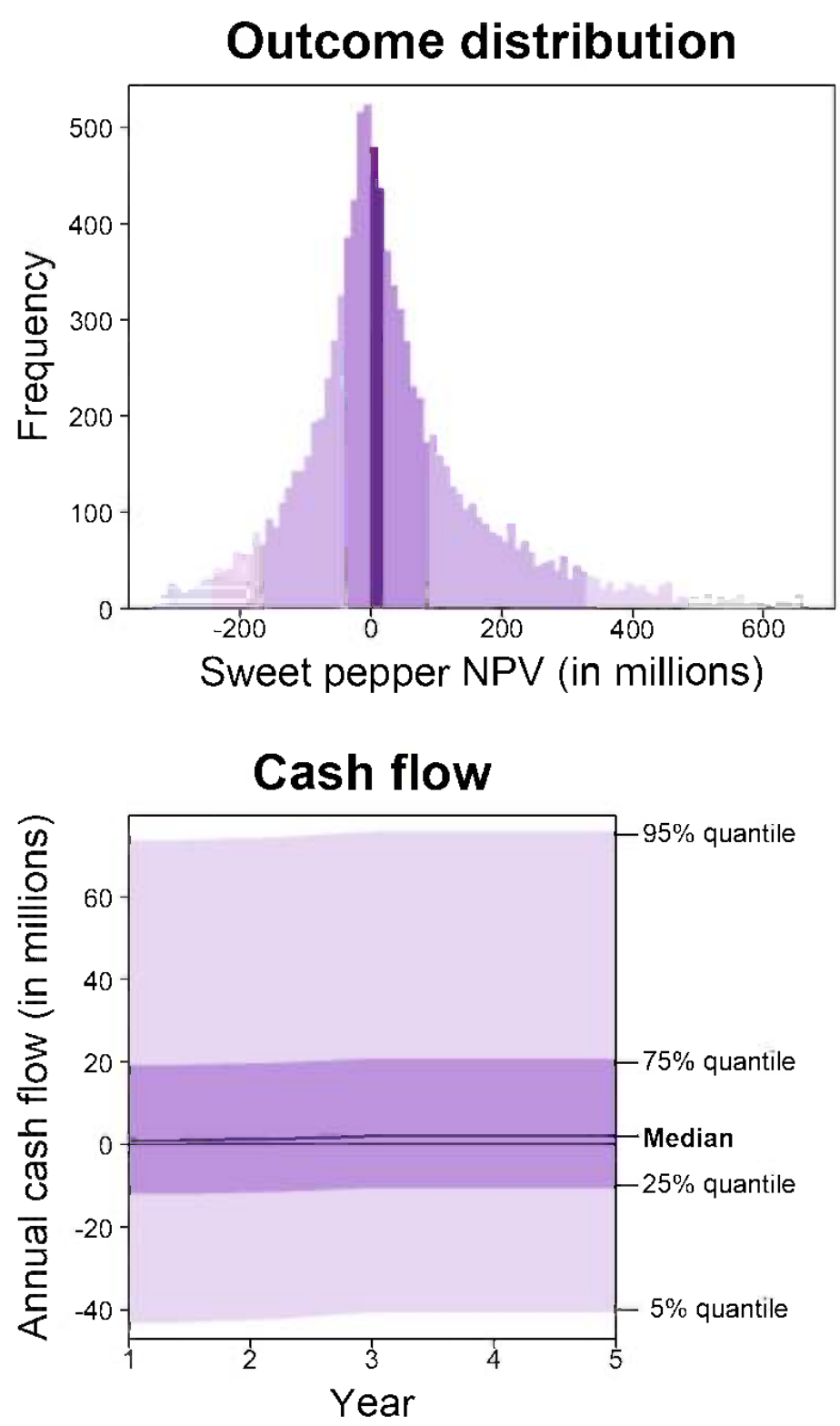
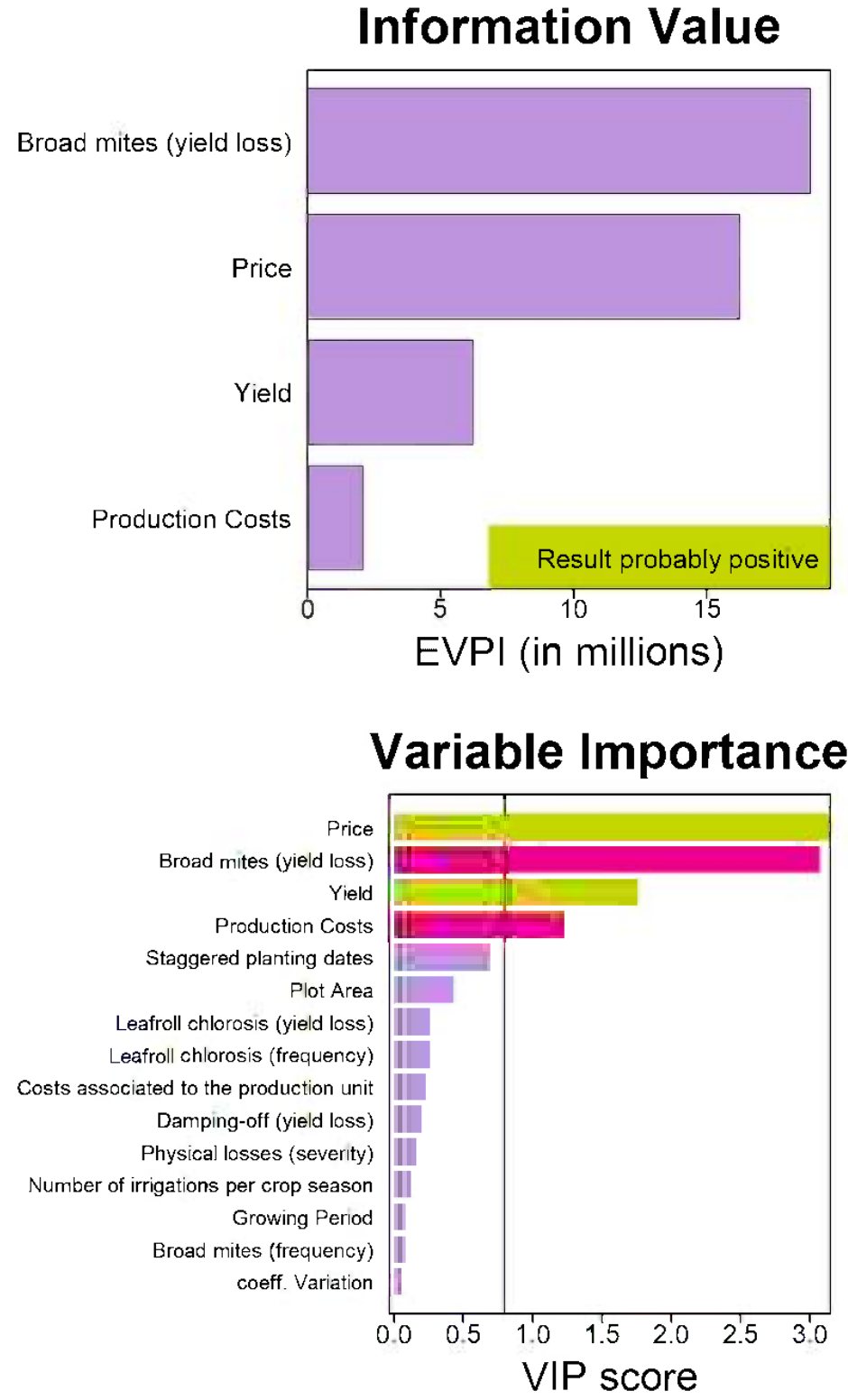

Figura 3. Resultados del modelo de simulación para la producción de ají dulce (sweet pepper) en los sistemas irrigados de producción hortícola de Valle del Sinú, Córdoba, Colombia (con 10,000 ejecuciones de modelos) con un horizonte temporal de cinco años. Outcome Distribution: Distribución de utilidades proyectada en millones de pesos colombianos (mCOP) como valor presente neto (NPV) (arriba a la izquierda). Information Value: Valor de la información en mCOP estimada como Valor esperado de la información perfecta (EVPI) (arriba a la derecha). Cash Flow: Flujo de caja del cultivo en mCOP por año (abajo a la izquierda). Variable Importance: Importancia de las variables (VIP score) determinadas por regresión de mínimos cuadrados parciales. Las variables con un valor VIP > 0.8 (línea vertical negra) están marcadas en verde (correlación positiva) o en rosado (correlación negativa) (abajo a la derecha). 

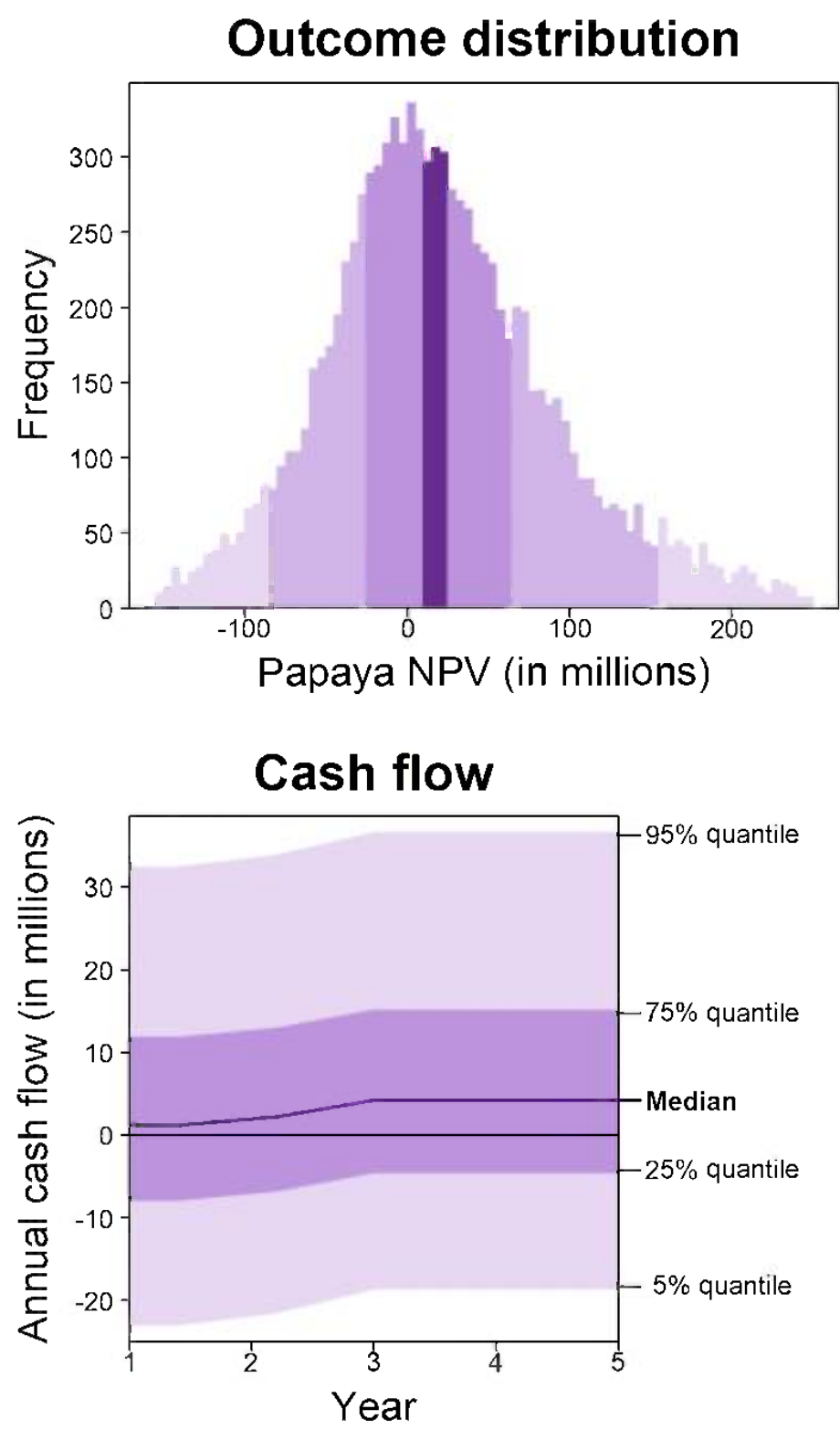
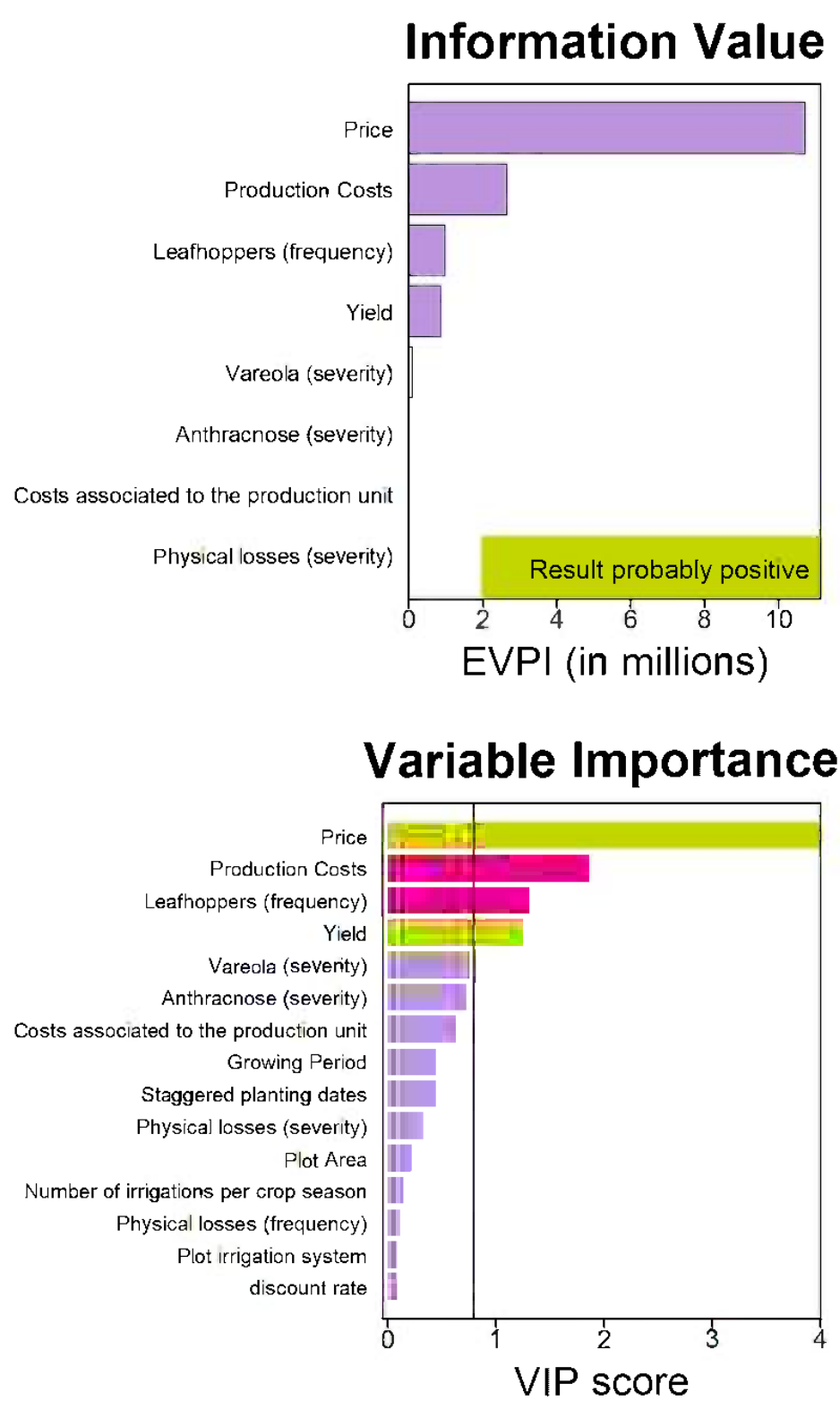

Figura 4. Resultados del modelo de simulación para la producción de papaya en los sistemas irrigados de producción hortícola de Valle del Sinú, Córdoba, Colombia (con 10,000 ejecuciones de modelos) con un horizonte temporal de cinco años. Outcome Distribution: Distribución de utilidades proyectada en millones de pesos colombianos (mCOP) como valor presente neto (NPV) (arriba a la izquierda). Information Value: Valor de la información en mCOP estimada como Valor esperado de la información perfecta (EVPI) (arriba a la derecha). Cash Flow: Flujo de caja del cultivo en mCOP por año (abajo a la izquierda). Variable Importance: Importancia de las variables (VIP score) determinadas por regresión de mínimos cuadrados parciales. Las variables con un valor VIP > 0.8 (línea vertical negra) están marcadas en verde (correlación positiva) o en rosado (correlación negativa) (abajo a la derecha). 

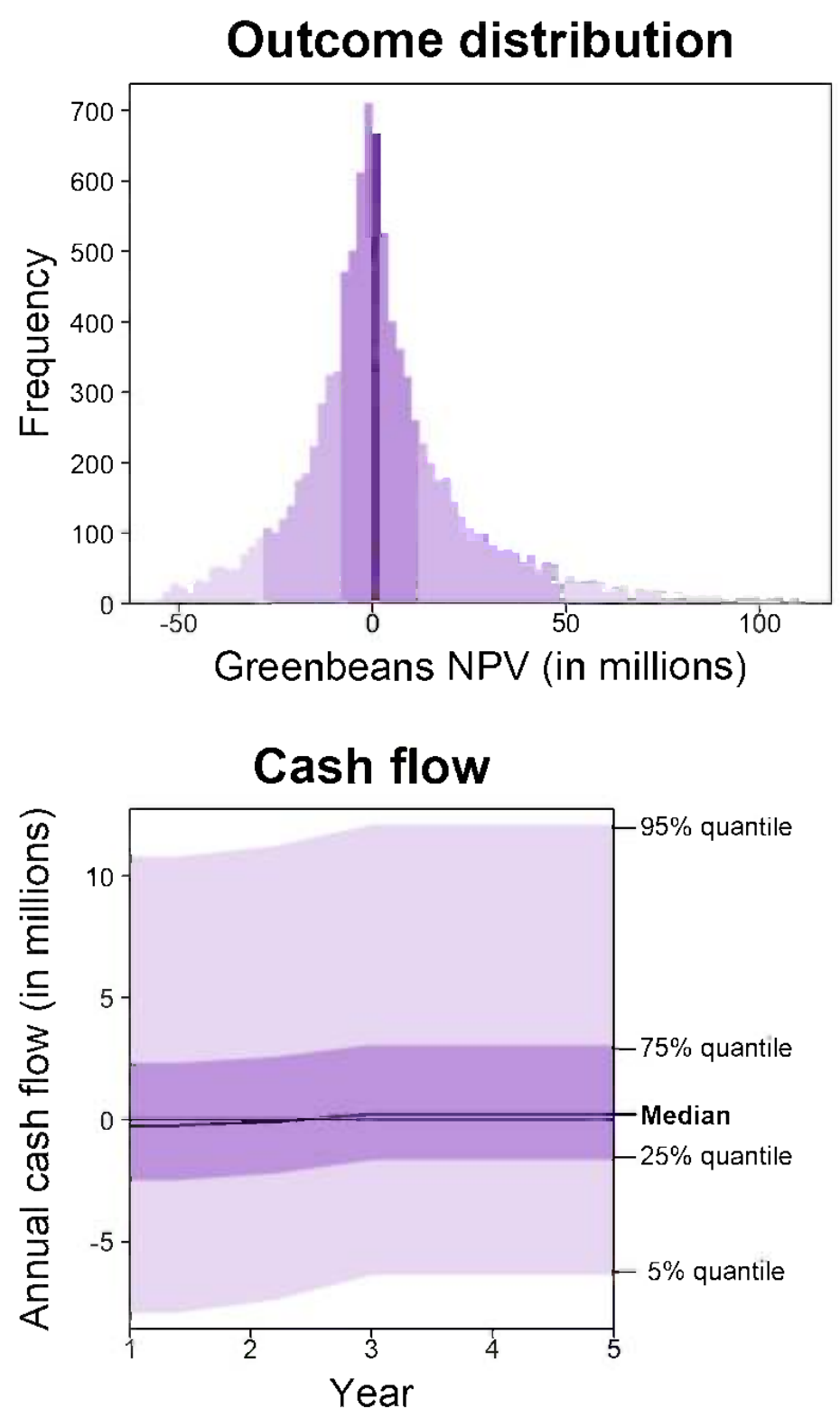

Information Value

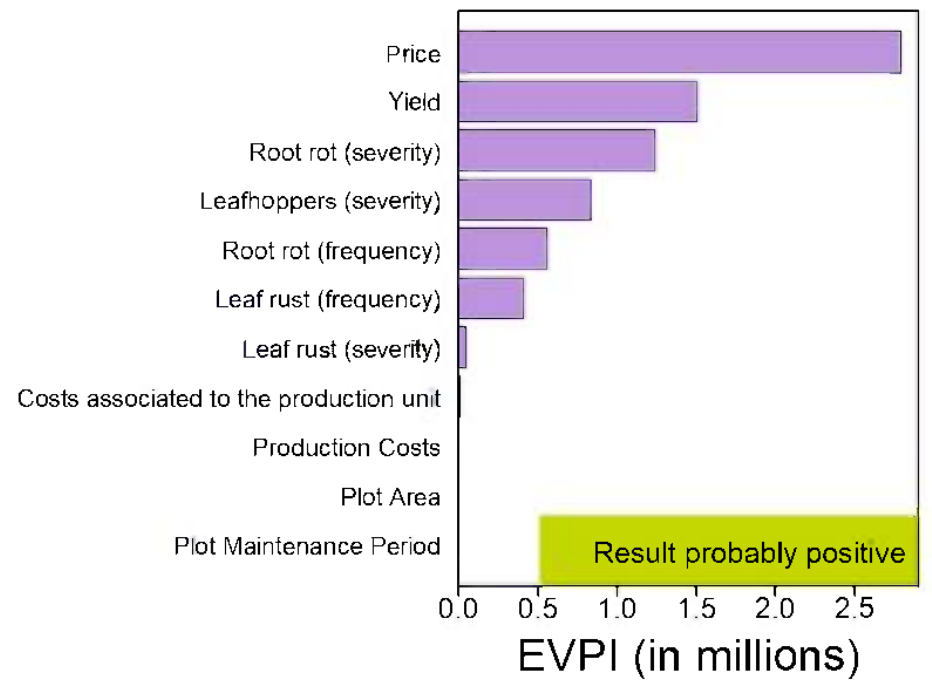

\section{Variable Importance}

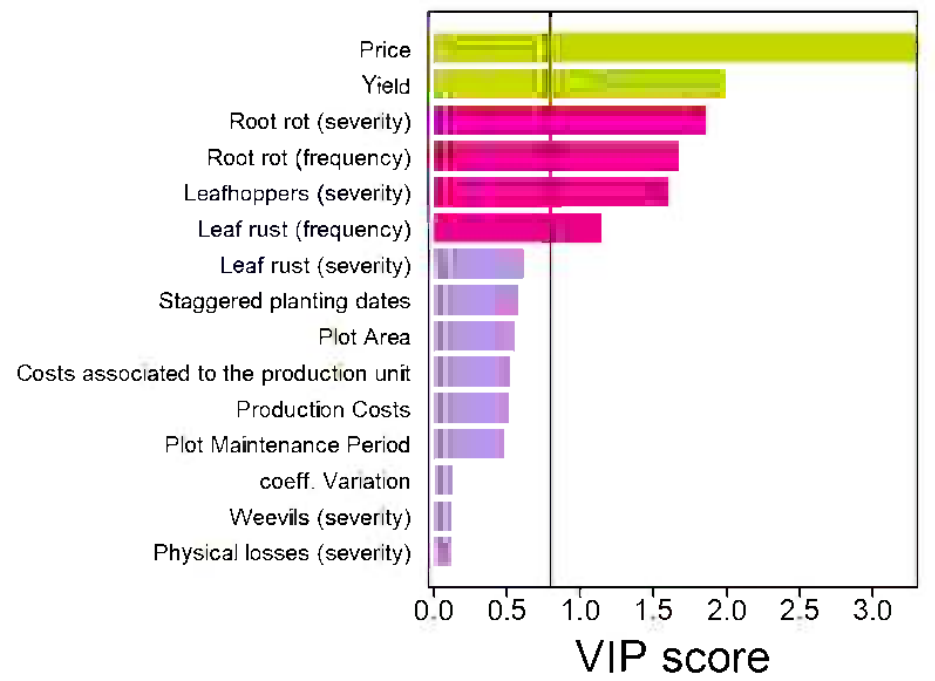

Figura 5. Resultados del modelo de simulación para la producción de habichuela larga (green beans) en los sistemas irrigados de producción hortícola de Valle del Sinú, Córdoba, Colombia (con 10,000 ejecuciones de modelos) con un horizonte temporal de cinco años. Outcome Distribution: Distribución de utilidades proyectada en millones de pesos colombianos (mCOP) como valor presente neto (NPV) (arriba a la izquierda). Information Value: Valor de la información en mCOP estimada como Valor esperado de la información perfecta (EVPI) (arriba a la derecha). Cash Flow: Flujo de caja del cultivo en mCOP por año (abajo a la izquierda). Variable Importance: Importancia de las variables (VIP score) determinadas por regresión de mínimos cuadrados parciales. Las variables con un valor VIP > 0.8 (línea vertical negra) están marcadas en verde (correlación positiva) o en rosado (correlación negativa) (abajo a la derecha). 
A

Profit distribution - NPV (in COP millions)

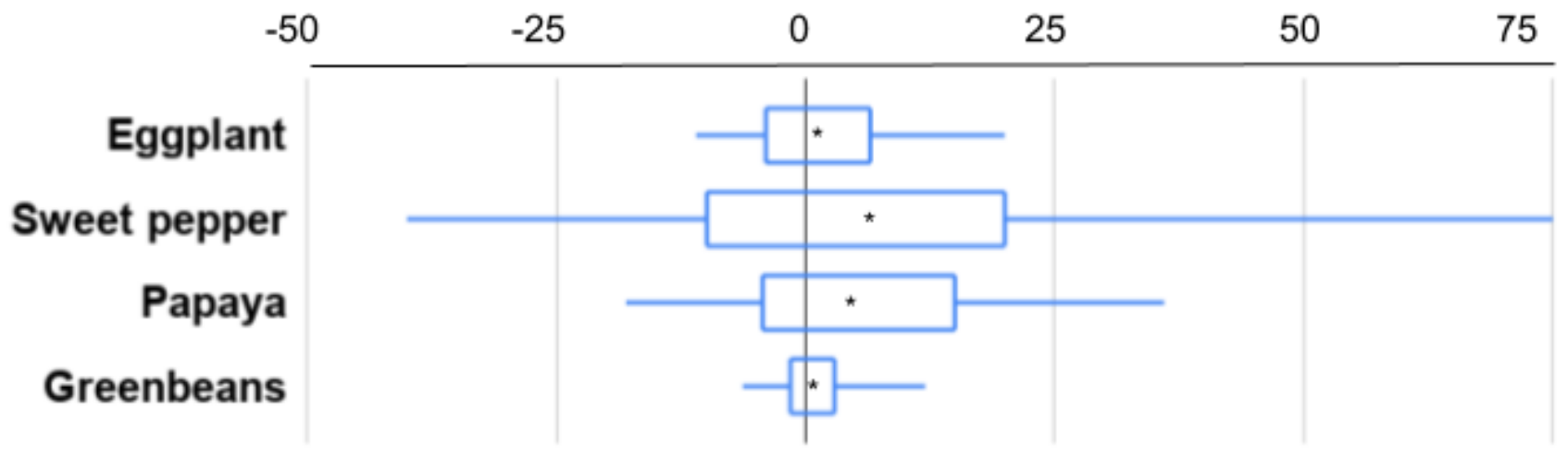

B

Benefit-Cost ratio distribution

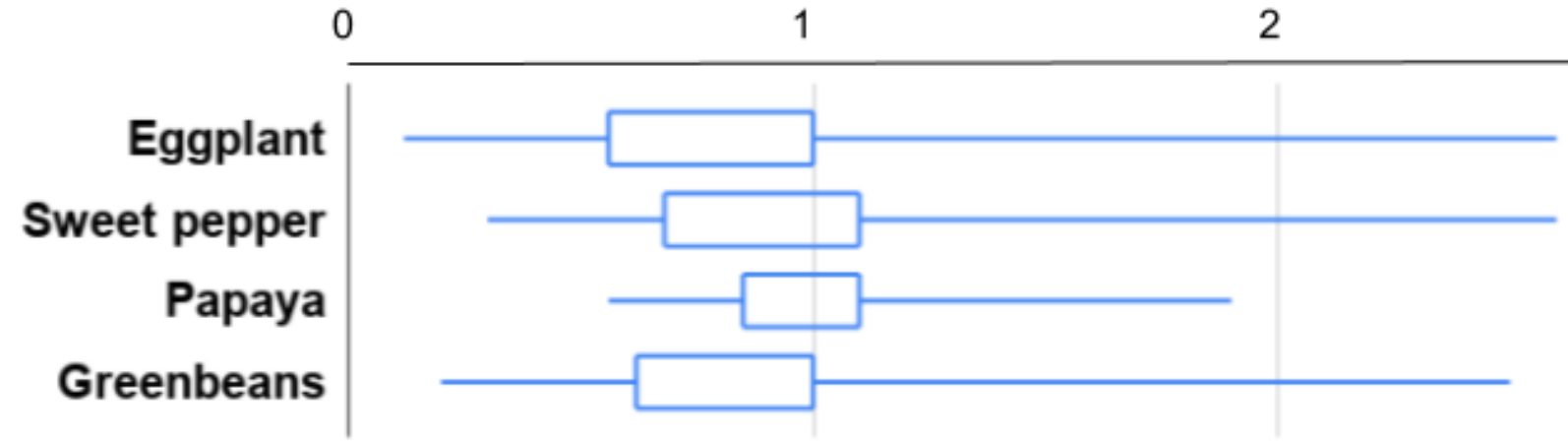

Figura 6. Intervalos de confianza para A.Valor presente neto (VPN) (millones de COP para el año 3) y B. relación beneficio-costo (RBC) de los cultivos utilizados en los sistemas de producción hortícola irrigados del Valle de Sinú, Córdoba, Colombia: berenjena (eggplant), ají dulce (sweet pepper), papaya, y habichuela larga (greenbeans). Los resultados se produjeron a través de la simulación de Monte Carlo (con 10,000 ejecuciones de modelos) con un horizonte temporal de cinco años. Para el valor presente neto se escogió solo un año para facilitar la evaluación de los rangos por parte de los agricultores (expertos). A partir del tercer año, los ingresos se mantienen estables para todos los cultivos como resultado del cubrimiento del costo de la inversión inicial durante los primeros dos años. Para cada cultivo en ambos paneles, la línea representa el intervalo de confianza 0 - $95 \%$ y la caja representa el intervalo entre el $25-75 \%$. El asterisco en panel A representa el promedio de los valores de la simulación. 
Tabla 3. Variables de alto valor identificadas para los principales cultivos utilizados en los sistemas de producción hortícola irrigados del valle de Sinú, Córdoba, Colombia.

\begin{tabular}{|c|c|c|c|c|c|c|c|c|}
\hline \multirow{2}{*}{ Cultivos } & \multicolumn{6}{|c|}{ EVPI (millones de pesos colombianos (COP)) ${ }^{*}$} & \multirow{2}{*}{ Plagas } & \multirow{2}{*}{ Enfermedades } \\
\hline & Precio & Rendimiento & $\begin{array}{l}\text { Costos de } \\
\text { producción }\end{array}$ & $\begin{array}{l}\text { Pérdidas } \\
\text { por plagas }\end{array}$ & $\begin{array}{l}\text { Frecuencia de } \\
\text { enfermedades }\end{array}$ & $\begin{array}{l}\text { Pérdidas por } \\
\text { enfermedades }\end{array}$ & & \\
\hline Berenjena & 4.18 & 0.33 & 0.36 & 1.39 & 2.42 & 1.24 & $\begin{array}{l}\text { Tetranychus } \\
\text { ludeni }\end{array}$ & $\begin{array}{l}\text { Marchitamiento } \\
\text { vascular }\end{array}$ \\
\hline Aji dulce & 16.24 & 6.22 & 2.06 & 18.91 & & & Acaro blanco & \\
\hline Papaya & 10.72 & 0.87 & 2.65 & 0.98 & & & Lorito verde & \\
\hline $\begin{array}{l}\text { Habichuela } \\
\text { larga }\end{array}$ & 2.80 & 1.51 & & 0.84 & 0.56 & 1.24 & Lorito verde & $\begin{array}{l}\text { Pudrición } \\
\text { radicular / Roya }\end{array}$ \\
\hline
\end{tabular}

* Las variables se identificaron utilizando el Valor esperado de información perfecta (EVPI) de los resultados producidos a través de la simulación de Monte Carlo (con 10,000 ejecuciones de modelos) con un horizonte temporal de cinco años. El EVPI es una estimación del efecto esperado si las brechas logran cerrarse y del impacto que las ofertas tecnológicas deben tener para cambiar los indicadores del sistema.

\section{Discusión}

La producción agrícola es una actividad de alto riesgo que requiere una comprensión de todas las limitantes a fin de garantizar la inversión e incrementar los ingresos de los agricultores además de reducir el impacto sobre los recursos naturales (Kimura et al., 2010; OECD, 2011). Los pequeños agricultores en el trópico enfrentan un elevado número de riesgos que limitan su capacidad para obtener suficiente alimento y obtener un ingreso estable: brotes de plagas y enfermedades, eventos climáticos extremos, y variaciones repentinas de precios en el mercado. Al depender principalmente de la actividad agrícola para obtener sus ingresos y limitados recursos financieros y capacidad para enfrentar eventos desafortunados, cualquier reducción en la productividad agrícola tiene un impacto significativo en su seguridad alimentaria, nutrición, ingreso económico y bienestar (Harvey et al., 2014; Hertel and Rosch, 2010; McDowell and Hess, 2012; Morton, 2007; O'Brien et al., 2004)

Los sistemas de producción hortícolas emplean un amplio rango de diferentes cultivos que aunque favorece la diversificación en el uso de la tierra, también incrementan la complejidad del sistema. Agricultores e investigadores dedicados a estos sistemas deben reconocer cuales son los factores que limitan las especies vegetales seleccionadas y que componentes del sistema agrícola deben ser abordados para incrementar el retorno económico (Paut et al., 2019). Este estudio de los sistemas irrigados de producción de hortalizas en el Valle del Sinú (SIPH-VS) tiene como propósito asistir a los agricultores durante la decisión de seleccionar los cultivos donde invertirán sus recursos y proveer a investigadores vinculados a AGROSAVIA y otras instituciones locales de una guía orientadora en sus esfuerzos de apoyar a los horticultores de esta región. Los sistemas de producción de hortalizas están compuestos por múltiples especies vegetales lo que dificulta el proceso de priorización de los esfuerzos de investigación. En el caso de AGROSAVIA y la red de hortalizas este proceso es mucho más complejo porque debe atender con limitados recursos financieros los sistemas de producción de 
hortalizas del país. Estos exhiben una enorme diversidad ambiental y biológica en consideración a la diversidad de las regiones geográficas del país. El protocolo aquí presentado permite desarrollar este proceso de priorización de recursos y maximizar la inversión pública en investigación con el propósito de incrementar los ingresos de los agricultores ${ }^{5}$.

\section{Variables con los valores de información más altos}

El valor esperado de la información o EVPI (expected value of perfect information) es la diferencia entre el valor esperado de una decisión tomada con la información perfecta y el valor esperado de la decisión tomada con la información actual. EVPI está expresado en unidades monetarias como el estimado que un tomador de decisiones estaría dispuesto a pagar para poder tener acceso a la información perfecta (Hubbard Decision Research, 2015; Strong et al., 2014). Para este estudio, es el beneficio económico esperado de actualizar cada uno de los parámetros de entrada o variables en cada uno de los modelos que representan los cultivos. Las variables con el EVPI más alto pueden ser consideradas prioridades para mediciones adicionales que permitirán reducir la incertidumbre en la decisión a tomar y en esta caso particular facilitar el proceso de priorización de problemas de investigación. Volver a tomar medidas de una variable específica priorizada por el EVPI y volver a desarrollar el análisis con la nuevos datos provee de más claridad a los resultados y permite el diseño y priorización de investigaciones futuras o estimar el efecto esperado en el indicador del sistema de cambios en las variables de entrada (Hubbard Decision Research, 2015; Luedeling et al., 2015; Rosenstock et al., 2014; Strong et al., 2014).

Las variables con los valores EVPI más altos en los cultivos seleccionados del SPIH-VS son las que describen el precio de venta de los productos. Los agricultores tienen relativamente poca influencia en la determinación del precio, aunque ellos tienen preferencias por ciertas fechas de siembra a fin de de cosechar en ventanas de tiempo donde esperan los mejores precios. Entre las variables de precio, el ají dulce es el cultivo que exhibe el mayor valor de la información de los cultivos del SIPH-VS (aproximadamente 16 millones COP). Los expertos consultados describen un amplio rango para esta variable y una ventana de tiempo con precios extremadamente altos (Semana Santa). En términos generales, los expertos afirman que los precios de venta son difíciles de predecir y en consecuencia es preferible tener varias fechas de siembra con el propósito de incrementar la oportunidad de capturar mejores precios. Los precios actuales sugieren que los retornos son muy bajos o negativos cuando el precio alcanza la mitad inferior del rango reportado. Es crítico analizar para cada uno de los cultivos cuales son los factores que afectan el precio, por ej.: acceso a mercados formales, explotación por intermediarios y ausencia de cadena de valor formalizada.

La siguiente variable en importancia para el desempeño de los cultivos del SIPH-VS son las pérdidas asociadas a la presencia de plagas y enfermedades. Es especialmente importante, los ataques del ácaro blanco (Polyphagotarsonemus latus) en ají dulce cuyo valor de la información (19 millones COP) supera al del precio individual de los cultivos evaluados. En los cultivos analizados en este estudio, plagas y enfermedades agregadas tienen un efecto similar sobre los ingresos del agricultor al provocado por el precio. Pérdidas en este trabajo fueron estimadas como una medida de la severidad de estos factores biológicos sobre el rendimiento del cultivo. Un análisis de la dinámica de estos factores en diferentes épocas del año usando la información provista por los agricultores permitirá diseñar experimentos de campo que sean relevantes para cubrir la brecha de información que identificada por este modelo.

El rendimiento potencial es también una de las variables que influyen sobre los ingresos para el cual

${ }^{5}$ Este protocolo puede ser extendido para evaluar como indicadores relacionados con los objetivos de desarrollo sostenible (ODS). 
la información adicional puede ser colectada. La distancia entre los valores máximos y promedio reportados por los agricultores corresponden a brechas de rendimientos que pueden ser eliminadas transfiriendo la tecnología actualmente disponible para los agricultores más exitosos. Adicionalmente, existe una brecha de potencial biológica en estos cultivos que puede ser explotada. Tres de estos sistemas emplean landraces: berenjena, ají dulce y habichuela. Estos landraces producen frutos de características fisicoquímicas que cumplen con las preferencia del mercado local pero exhiben variaciones significativas de rendimiento. Un estudio previo encontró en landraces de berenjena del Valle del Sinú variaciones significativas en rendimiento y resistencia a plagas entre los landraces. Inclusive, algunos agricultores han desarrollado a través de selección poblaciones de berenjenas de alto rendimiento. HORTIFRU tiene una iniciativa para obtener el registro legal de poblaciones mejoradas de berenjena como variedades comerciales. En este caso, en consideración que rendimiento y factores biológicos están relacionados, es necesario el desarrollo de un modelo especifico para explicar el rendimiento con la incorporación de información adicional de rangos y variables que explican esta interacción. Este modelo futuro provera de orientación a los experimentos de campo que deben estar orientados para cubrir la brecha de información que el modelo de rendimiento haya identificado.

\section{Comparación de cultivos por distribución de ingreso (NPV) y proporción costo-beneficio (BCR)}

Los modelos sugieren que el NPV de los ingresos esperados para los cultivos usados en los agricultores tienen un $50 \%$ de chances de pérdidas, principalmente asociada a la variación de precios y a las diferencias tecnológicas entre los agricultores (que corresponden a las variaciones exhibidas en rendimiento y manejo de plagas y enfermedades). La cadena de valor de hortalizas no cuenta con canales adecuados de mercadeo que permita garantizar los mejores precios a todos los agricultores. Los riesgos relacionados con la producción (rendimiento y las limitantes sanitarias) requiere transferencia de tecnología y desarrollo de estrategias con destino a las unidades de producción. Es importante que instituciones como AGROSAVIA trabaje con los agricultores para obtener mayor información sobre esas variables y como ellas influencian los ingresos de los agricultores a fin de desarrollar las mejores estrategias de intervención. En el caso de los riesgos asociados al mercado, estos requieren estrategias de extensión que permitan el acceso a mercados formales. Considerando, los valores de EVPI, es importante recoger más información sobre estas variables (producción y mercadeo) y verificar cómo estás influencia el NPV.. La productividad es una función que depende de varios factores. Un futuro modelo o intervenciones deben considerar el análisis o intervención de los factores aquí encontrados que permitan asegurar el incremento de los ingresos.

Las diferencias en NPV y BCR de los cultivos evaluados no permiten una clara discriminación entre ellos que permita afirmar que uno de ellos es una mejor alternativa que los otros. El análisis BCR muestra rangos solapantes para los cuatro cultivos evaluados (similares para tres de ellos). A similares valores de BCR, la preferencia de los agricultores por cada uno de estos cultivos está justificada por otros factores. Los mayores ingresos de papaya y ají dulce corresponden a mayor inversión, costos de producción y flujo de caja que requiere capital financiero al cual los agricultores no tienen acceso similar y que cambia a lo largo del tiempo. Usando la información provista por los agricultores, los resultados observados en la simulación pueden ser explicados como sigue. Los agricultores más pequeños o en necesidad de obtener efectivo de manera rápida recurren a la siembra de habichuela larga que genera menores ingresos pero requiere una inversión menor y con un ciclo vegetativo mucho más corto. Aquellos agricultores con mayor experiencia con capacidad para manejar unidades de producción de mayor tamaño y conseguir mercados más amplios para sus productos optan por sembrar papaya y aji dulce. Estos dos cultivos requieren mayor capital 
financiero para cubrir una inversión inicial mayor, mayores costos de producción y en el caso de la papaya un mayor periodo vegetativo. Recolección adicional de información debe proveer una explicación cuantitativa para estas últimas afirmaciones.

La metodología presentada puede ser usado en la identificación de las necesidades críticas de investigación que las redes de AGROSAVIA deben abordar en consideración al costo de oportunidad de sus recursos (priorización), a su misión institucional ${ }^{6}$ y el escenario de acción esperado en el 2027 (CORPOICA, 2016) ${ }^{7}$. Este trabajo en particular es un ejemplo para el alcance de los logros asociados al Objetivo Estratégico 1: "incrementar la productividad y competitividad de los sistemas productivos agropecuarios para el cambio técnico y la generación de valor mediante actividades de I+D+i y soluciones enfocadas en las demandas" (CORPOICA, 2016). En este caso en particular los beneficios esperados para el agricultor fueron estimados para cada uno de los cultivos empleados en el sistema de producción como una representación de la productividad y las futuras actividades de I+D+i pueden ser priorizadas en función del impacto que las variables del sistema tienen sobre el indicador a evaluar. Esta metodología también puede ser usada para estimar qué efecto se espera de las ofertas tecnológicas a desarrollar sobre el desempeño del sistema productivo (implementación) ${ }^{8}$.

\section{Recomendaciones}

El precio de venta de los productos y las limitantes sanitarias son las principales variables afectando los ingresos de los agricultores y es en donde los esfuerzos de investigación e intervención deben estar concentrados.. El riesgo de pérdidas en los cultivos empleados en el SIPH-VS es del $50 \%$, lo que sugiere la necesidad de monitorear las variables críticas identificadas con el propósito de reducir las probabilidades de resultados negativos.

Las principales fuentes de riesgo en las operaciones agrícolas están asociadas a la variabilidad en la producción y los precios. La primera categoría incluye los riesgos asociados a la presencia de factores limitantes y reductores del rendimiento de los cultivos, mientras la segunda categoría describe los riesgos relacionado con el mercado (Kimura et al., 2010; OECD, 2011). Entre los cultivos evaluados los ingresos esperados más altos corresponden al ají dulce. La mayor variación de precio del ají dulce también explica porqué las variables de rendimiento e impacto de plagas y enfermedades relacionadas a este cultivo exhiben los mayores valores de importancia. Es recomendable colectar más información de estas variables que permite incrementar la precisión de los modelos aquí presentados.

\section{Futuras aplicaciones de las simulaciones probabilísticas de sistemas agrícolas}

La determinación de los costos, beneficios y riesgos de los sistemas de producción agrícola exhibe altos niveles de incertidumbre. Las futuras intervenciones en los sistemas de producción de

\footnotetext{
${ }^{6}$ Coordinar, focalizar, dar prioridad y hacer más pertinente la gestión de conocimiento de la investigación, el desarrollo tecnológico y la innovación $(\mathrm{I}+\mathrm{D}+\mathrm{i})$ para el cambio técnico y la generación de valor de la industria agraria nacional, orientado a mejorar su sostenibilidad, productividad y competitividad con enfoque territorial y fortalecer el Sistema Nacional de Ciencia y Tecnología Agroindustrial (SNCTA) con capital social, infraestructura científica, mecanismos de financiamiento y marcos de gobernanza para lograrlo.

${ }^{7}$ CORPOICA cambió su nombre de marca comercial a mediados del 2018 a AGROSAVIA.

${ }^{8}$ Para 2027, el país contará con un sistema de innovación agropecuario activo y coordinado en el ámbito nacional y territorial,que habrá contribuido al aumento de la sostenibilidad, la competitividad y la productividad sectorial, al mejoramiento de la calidad e inocuidad de la oferta alimentaria nacional y del capital social necesario para una adecuada gobernanza de los recursos públicos de inversión en actividades y capacidades en CTi, apoyada por mecanismos de seguimiento y evaluación efectivos.
} 
hortalizas deben ser conscientes de estas incertidumbres y usar un enfoque como el aquí propuesto para la evaluación de estas intervenciones y para decidir dónde invertir los recursos de investigación. Los sistemas de producción de hortalizas en el Caribe particularmente son marginales, sin incorporación de tecnología y basados en landraces, y con limitada inversión pública y privada.

La planificación de las tareas de investigación y el desarrollo de intervenciones en el caso de la red de hortalizas de AGROSAVIA requiere enfrentar multiples sistemas de producción en ambientes dispares con una enorme diversidad de especies vegetales. En esta red, en consideración de la complejidad y las limitaciones de recursos financieros, el paso más importante a tener claro en este proceso es como tomar estas decisiones de inversión de esfuerzos y dinero que maximicen el efecto sobre el ingreso de los agricultores. Este proceso requiere estimar las incertidumbres y los riesgos asociados a los sistemas de producción de las regiones (incluyendo las especies vegetales de cada sistema), establecer una visión a largo plazo de las acciones a desarrollar en estos sistemas de producción y establecer prioridades de inversión de recursos de investigación. El desarrollo de modelos y simulaciones usando un proceso participativo con un enfoque sistémico como el aquí presentado es una solución factible para desarrollar este proceso de toma de decisiones.

Este enfoque permite además la identificación y priorización de incertidumbres críticas en el sistema que se constituyen en las brechas de conocimiento que deben ser atendidas. Estas deben ser cuantificadas primero usando un enfoque similar al aquí presentado antes de implementar ensayos de laboratorio, experimentos de campo o intervenciones. Este tiene el potencial de incrementar la efectividad en términos de costos del proceso de toma de decisiones para orientar las labores de investigación y desarrollo de intervenciones en los sistemas agrícolas (y en el largo plazo un mejor apoyo de la investigación en el desarrollo de políticas públicas).

Este enfoque además presenta un claro ejemplo de negocio de análisis de inversiones en el sector agrícola para pequeños productores y en sistemas marginales de producción. Así que no solo provee de información a los investigadores de las instituciones sino que puede ser usado por inversores (ONGs o gobierno local) que desean implementar intervenciones agrícolas con recursos limitados.

\section{Conclusiones}

Los sistemas de producción de hortalizas requieren un análisis de las opciones de inversión de cada una de las especies utilizadas que permitan la maximización del ingreso para los agricultores. Esto puede alcanzarse a través de proyecciones probabilísticas de ingresos desagregados por cada cultivo. Las intervenciones el sistema productivo o en cada uno de estos cultivos también pueden evaluarse siguiendo este enfoque. Este estudio estimó el ingreso esperado para los cultivos del sistema irrigado de producción de hortalizas para el Valle del Sinú y la importancia de las variables cada uno de estos sistemas productivos.

El desarrollo de investigaciones, ofertas tecnológicas o intervenciones para el sector agrícola requiere que están sean diseñadas para cumplir con los requerimientos económicos, sociales y ambientales de las comunidades rurales. Así que quienes toman las decisiones requieren análisis ex-ante de las opciones de inversión. Los análisis de riesgo y costo-beneficio de intervenciones en los sistemas de producción agrícola deben considerar todos los factores que son relevantes para la implementación de la decisión a tomarse, aun de aquellos factores que inicialmente se consideran que no pueden ser medidos o para los cuales no hay datos. El enfoque aquí presentado permite la incorporación del conocimiento de los agricultores, asistentes técnicos e investigadores en un marco 
de comprensión que mejora significativamente la calidad de las decisiones tomadas.

El análisis de Valor de la información tiene la capacidad de proveer indicaciones de que se necesita medir para apoyar las decisiones de intervención o investigación. Las decisiones en sistemas complejos son afectados por multiples incertidumbres, pero solo aquellas incertidumbres que representan valor o utilizada para el tomador de decisiones deben ser priorizadas para mediciones adicionales u objeto de intervención. Este enfoque reduce de manera sustancial el costo de recolectar datos y entender la función de esta variables en el sistema con el propósito de incrementar la productividad del sistema o tomar mejores decisiones.

\section{Bibliography}

Chapin, F.S., Matson, P.A., Mooney, H.A., 2002. Landscape heterogeneity and ecosystem dynamics, in: Principles of Terrestrial Ecosystem Ecology. Springer New York, New York, NY, pp. 305-331. doi:10.1007/0-387-21663-4_14

CORPOICA, 2016. PECTIA. Plan estratégico de ciencia, tecnología e innovación agropecuaria del sector agropecuario colombiano (2017-2027). CORPOICA.

CVS, 2019. Cobertura geográfica $\star$ Corporación Autónoma Regional de Los Valles del Sinu y del San Jorge [WWW Document]. URL https://cvs.gov.co/web/cobertura-geografica/ (accessed 12.18.19).

García-Llamas, P., Calvo, L., De la Cruz, M., Suárez-Seoane, S., 2018. Landscape heterogeneity as a surrogate of biodiversity in mountain systems: What is the most appropriate spatial analytical unit? Ecological Indicators 85, 285-294. doi:10.1016/j.ecolind.2017.10.026

Harvey, C.A., Rakotobe, Z.L., Rao, N.S., Dave, R., Razafimahatratra, H., Rabarijohn, R.H., Rajaofara, H., Mackinnon, J.L., 2014. Extreme vulnerability of smallholder farmers to agricultural risks and climate change in Madagascar. Philos. Trans. R. Soc. Lond. B. Biol. Sci 369, 20130089. doi:10.1098/rstb.2013.0089

Hertel, T.W., Rosch, S.D., 2010. Climate change, agriculture and poverty, Policy research working papers. The World Bank. doi:10.1596/1813-9450-5468

Hubbard, D.W., 2010. How to measure anything: Finding the value of intangibles in business, 2nd ed. John Wiley \& Sons, New Jersey, NJ.

Hubbard Decision Research, 2015. How to Measure Anything.

IGAC, 2017. Producción agropecuaria en los grandes Distritos de riego de Colombia ha sido improvisada: IGAC | Instituto Geográfico Agustín Codazzi [WWW Document]. Instituto Geográfico Agustín Codazzi. URL

https://www.igac.gov.co/es/noticias/produccion-agropecuaria-en-los-grandes-distritos-de-riego-de -colombia-ha-sido-improvisada (accessed 2.17.20).

Kimura, S., Antón, J., LeThi, C., 2010. Farm level analysis of risk and risk management strategies and policies: cross country analysis (Working paper), OECD food, agriculture and fisheries papers. doi:10.1787/5kmd6b5rl5kd-en

Loughlin, N.J.D., Gosling, W.D., Coe, A.L., Gulliver, P., Mothes, P., Montoya, E., 2018. Landscape-scale drivers of glacial ecosystem change in the montane forests of the eastern Andean flank, Ecuador. Palaeogeography, Palaeoclimatology, Palaeoecology 489, 198-208. 
doi:10.1016/j.palaeo.2017.10.011

Luedeling, E., Oord, A.L., Kiteme, B., Ogalleh, S., Malesu, M., Shepherd, K.D., De Leeuw, J., 2015. Fresh groundwater for Wajirâ€"ex-ante assessment of uncertain benefits for multiple stakeholders in a water supply project in Northern Kenya. Front. Environ. Sci. 3. doi:10.3389/fenvs.2015.00016 MADR, Gobernación de Cordoba, FNFH, ASOHOFRUCOL, SAG, 2006. Desarrollo de la fruticultura en Córdoba, Plan Fruticola Nacional. Fondo Nacional de Fomento Hortifrutícola, Monteria.

McDowell, J.Z., Hess, J.J., 2012. Accessing adaptation: Multiple stressors on livelihoods in the Bolivian highlands under a changing climate. Global Environmental Change 22, 342-352. doi:10.1016/j.gloenvcha.2011.11.002

Morton, J.F., 2007. The impact of climate change on smallholder and subsistence agriculture. Proc Natl Acad Sci USA 104, 19680-19685. doi:10.1073/pnas.0701855104

OECD, 2011. Managing risk in agriculture: policy assessment and design. OECD. doi:10.1787/9789264116146-en

Ortiz Guerrero, C.E., Pérez Martínez, M.E., Muñoz Wilches, L.A. (Eds.), 2007. Los cambios institucionales y el conflicto ambiental: el caso de los valles del río Sinú y San Jorge.

O'Brien, K., Leichenko, R., Kelkar, U., Venema, H., Aandahl, G., Tompkins, H., Javed, A., Bhadwal, S., Barg, S., Nygaard, L., West, J., 2004. Mapping vulnerability to multiple stressors: climate change and globalization in India. Global Environmental Change 14, 303-313. doi:10.1016/j.gloenvcha.2004.01.001

Paut, R., Sabatier, R., Tchamitchian, M., 2019. Reducing risk through crop diversification: An application of portfolio theory to diversified horticultural systems. Agric. Syst. 168, 123-130. doi:10.1016/j.agsy.2018.11.002

Rosenstock, T.S., Mpanda, M., Rioux, J., Aynekulu, E., Kimaro, A.A., Neufeldt, H., Shepherd, K.D., Luedeling, E., 2014. Targeting conservation agriculture in the context of livelihoods and landscapes. Agriculture, Ecosystems \& Environment 187, 47-51. doi:10.1016/j.agee.2013.11.011

Strong, M., Oakley, J.E., Brennan, A., 2014. Estimating multiparameter partial expected value of perfect information from a probabilistic sensitivity analysis sample: a nonparametric regression approach. Med. Decis. Making 34, 311-326. doi:10.1177/0272989X13505910 